\title{
Hereditary myopathy with lactic acidosis, succinate dehydrogenase and aconitase deficiency in northern Sweden: a genealogical study
}

\author{
Ulf Drugge, Monica Holmberg, Gösta Holmgren, Bela G L Almay, Håkan \\ Linderholm
}

\begin{abstract}
A hereditary myopathy with lactic acidosis during physical exercise, low physical work capacity, and paroxysmal myoglobinuria (HML), called "Myopathy with deficiency of succinate dehydrogenase and aconitase" (McKusick 255125) has been described in 19 members of nine families who lived in two geographically separate areas in northern Sweden. By using the unique Swedish historical archives, including Catechetical Meeting Records from a number of northern Swedish parishes, it has been possible to trace ancestors of the nine families including all known 19 cases back in time to some key couples, who lived up to 300 years ago (that is seven to ten generations). No common single couple or common links between families in the past was found in these registers as a support for a single or several mutations that had developed far back in time. The mode of inheritance in this family is most likely autosomal recessive. This material will be used for the chromosomal localisation of the gene.
\end{abstract}

( $\mathcal{F}$ Med Genet 1995;32:344-347)

Research Archives and Department of Sociology, University of Umeå, Sweden U Drugge

Department of Neurology, University of Umeå, S-90185 Ưmeå, Sweden

B G L Almay

Department of Clinical Genetics Applied Cell \& Molecular Biology, University of Umeå S-90185 Umeå,

Sweden

M Holmberg

G Holmgren

Department of Clinical Physiology, University of Umeå S-90185 Ưmeå, Sweden

$\mathrm{H}$ Linderholm

Correspondence to: Dr Holmgren.

Received 18 October 1994 Revised version accepted for publication 16 January 1995

A myopathy with lactic acidosis during physical exercise, low physical work capacity, and paroxysmal myoglobinuria (HML) called "Myopathy with deficiency of succinate dehydrogenase and aconitase" (McKusick $255125)^{1}$ was originally described in 14 patients from five families, ${ }^{23}$ all living in the northern part of Sweden. Since then, five other patients from four families have been described. All 19 patients from nine families lived in two geographically separate areas in northern Sweden. The disease has not been described previously and is another example of the many genetic diseases found in the sparsely populated circumpolar areas. ${ }^{4}$ In six of the patients from four families, a low activity of succinate dehydrogenase (SDH), aconitase, and some other enzyme and mitochondrial abnormalities have been found in skeletal muscle biopsies ${ }^{57}$ (unpublished results). Of other tissues, only the liver has been examined but did not show SDH deficiency (I Holme, personal communication).

The aim of this study was, if possible, to trace ancestors of these families back in time to some key couples by making use of the unique Swedish historical archives, including Catechetical Meeting Records from a number of north Swedish parishes, ${ }^{89}$ and to strengthen the diagnosis in sporadic cases in some of the families. If they were found within the pedigree frame the sporadic cases were linked to familial cases.

\section{Patients}

Out of 19 diagnosed patients 16 are still alive. The 19 patients belong to nine separate families, A to I, with healthy parents and 26 healthy sibs. Of these families, A to $\mathrm{E}$ were described during the $1960 \mathrm{~s}^{23}$ Family $\mathrm{A}$ includes four patients out of eight sibs, family B two out of seven sibs, family $\mathrm{C}$ three out of three sibs, family $D$ four out of eight sibs, and family $E$ one out of seven sibs. Family $F$ includes one patient out of two sibs, ${ }^{10}$ family $G$ two of six sibs, ${ }^{510-13}$ family $H$ one of two sibs ${ }^{67}$ (unpublished results), and finally one patient of two sibs in family $\mathrm{I}$, who was not included in the recent surveys of the disease, ${ }^{12-14}$ but was accepted as a patient with the disease because of a typical clinical history, hospital records and pedigree analysis. He died in hospital at the age of 14 years (table).

The case report of this boy, extracted from medical records, is presented below. A boy, born in 1972, had muscular weakness since early childhood. He was unable to take full part in physical exercise at school. Exercise tests on a bicycle ergometer at the age of 9 to 10 years showed low physical work capacity and high lactate blood concentration on high work loads. The nature of his disease was not understood.

At 14 years of age he performed heavy muscular work (pulling up a heavy boat) which led to an exacerbation of his disease. He developed severe muscular pain beginning in the calves

\begin{tabular}{lccl}
\multicolumn{5}{l}{ Affected and healthy sibs in families $A$ to $I$} \\
\hline Family & Total No of sibs & Affected sibs & Reference \\
\hline A & 8 & 4 & $2,3,14$ \\
B & 7 & 2 & 2 \\
C & 3 & 3 & 2,12 \\
D & 8 & 4 & 2 \\
E & 7 & 1 & 2 \\
F & 2 & 1 & 10 \\
G & 6 & 2 & $5,10-13$ \\
H & 2 & 1 & 6,7, unpubl \\
I & 2 & 1 & This report \\
Total & 45 & 19 & \\
\hline
\end{tabular}


and extending to the legs, stomach, and the whole body, with paresis of the legs. After one to two weeks his condition rapidly deteriorated. $\mathrm{He}$ was admitted to an intensive care unit almost unconscious with heart rate 120 beats/ minute, high respiratory rate, anuria, blood $\mathrm{pH}$ 6.99 , hyperkalaemia $7-10.3 \mathrm{mmol} / \mathrm{l}$, CK level 300-1409 (NV<3.3) $\mu \mathrm{kat} / \mathrm{l}, \mathrm{P}$-creatinine 124$234(\mathrm{~N}<100) \mu \mathrm{mol} / 1$. On the second day he died in circulatory shock with falling blood pressure in spite of intensive care treatment with artificial ventilation, oxygen, bicarbonate (Tribonat), albumin, plasma, peritoneal lavage, and dialysis.

Necropsy showed tubular nephritis (shock kidney). Microscopy showed striated skeletal muscles with marked variation of fibre size, some fibres without striation (hyalinised), and with vacuolisation.

Case reports of 12 other patients have been published. ${ }^{235-710-14}$ The symptoms, signs, and the clinical picture have been described in previous and recent papers. ${ }^{2312-14} \mathrm{~A}$ short summary is given below.

All the patients had a very low physical work capacity compared with healthy people, starting in early childhood onwards. Even after such activities as walking slightly uphill, the patients developed palpitations, dyspnoea, and muscle pains. Several of them had hypertrophy of the calves. The disease had a chronic course but sometimes an acute phase of the disease developed.

The patients had a normal maximum voluntary isometric muscle strength. ${ }^{3}$ In spite of that an exercise test on a bicycle ergometer showed a low exercise tolerance, one third of normal or less. Even at a low work load in absolute terms, these patients had a high heart rate, a high respiratory frequency, and high lactate and pyruvate concentrations in the blood. The patients complained of pains in the leg muscles during and after the exercise. $^{10}$

In the chronic stage the patients had a normal circulation at rest and normal blood lactate values. However, on exercise their circulation became extremely hyperkinetic, that is, the cardiac output was high in relation to oxygen uptake. The arteriovenous oxygen difference was low and the lactate concentration in the blood was abnormally high in relation to the exercise intensity. ${ }^{313}$

The heart function of these patients was normal and at maximum work intensity they reached a cardiac output and maximum heart rate comparable with that of normal subjects, although at a much lower physical work intensity. ${ }^{310}$ The oxygen saturation in blood from the femoral vein of exercising legs was high compared to normal subjects. ${ }^{313}$ The exercising muscles just could not take up the oxygen offered by the blood. The patient's work capacity on a bicycle ergometer was limited by the low arteriovenous oxygen difference, high heart rate, and a cardiac output which was maximal at a low work load, and also by intense pain in the working muscles.

Acute exacerbation of the disease may be initiated by prolonged straining exercise, starvation, or infections. It may be dramatic with extensive muscle paralysis, tachycardia, sometimes respiratory paralysis, severe acidosis, and myoglobinuria. In the most severe acute exacerbations of the disease circulatory shock may develop. Three out of our 19 known cases died in such an acute episode, in spite of intensive care, including attempts to buffer the metabolic acidosis, artificial respiration, and in one case plasmapheresis. ${ }^{12}$ Two other patients have been close to death in such acute attacks.

\section{Methods}

The genealogical analysis involved the following. After collecting information about ancestors born in the 20th century, parish registers converted to microfiches at the Research Archives, Umeå University, were studied. Families with affected subjects were then traced back as far as possible. ${ }^{15}$

The establishment of the Swedish parish registers took place at the end of the 17 th century according to a Church Law Act of 1686. The principal task was to keep catechetical meeting records in order to promote the ability to read and to understand basic religious tenets of the Protestant State

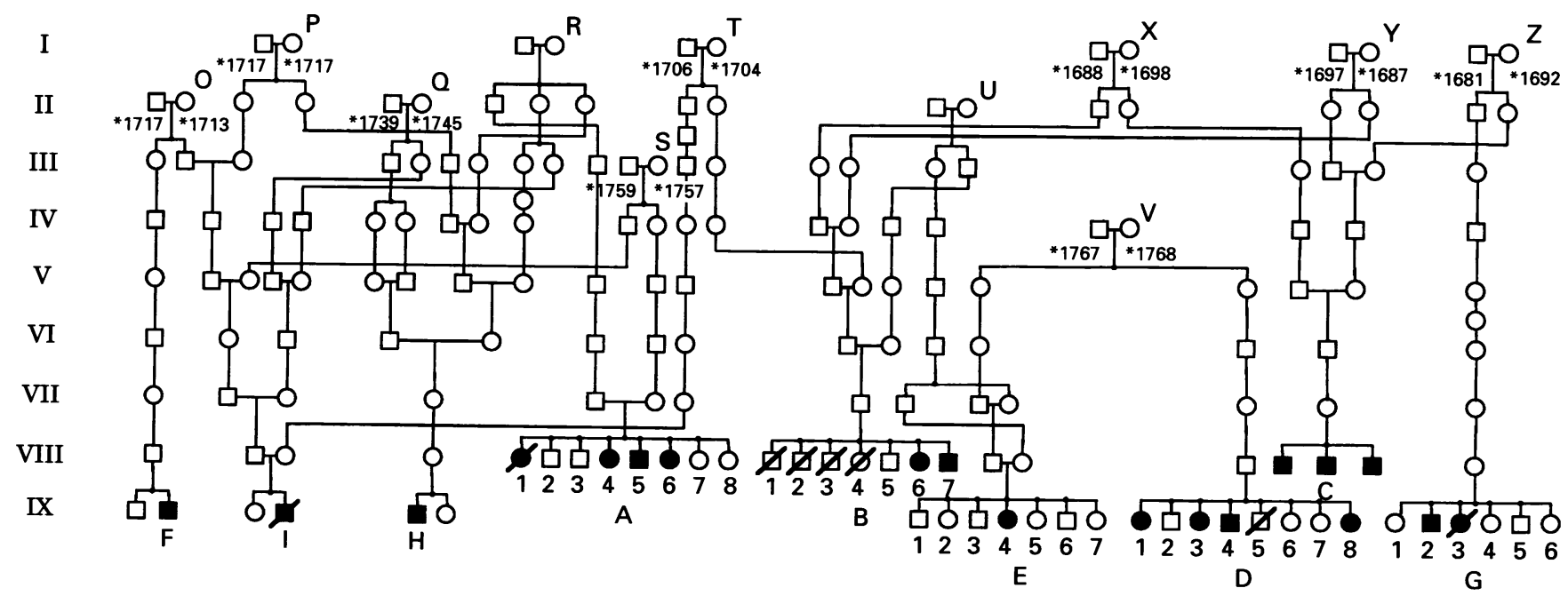

Figure 1 Pedigree with genealogical links between all known Swedish patients with HML. Black symbols denote affected persons and unfilled symbols healthy subjects. 


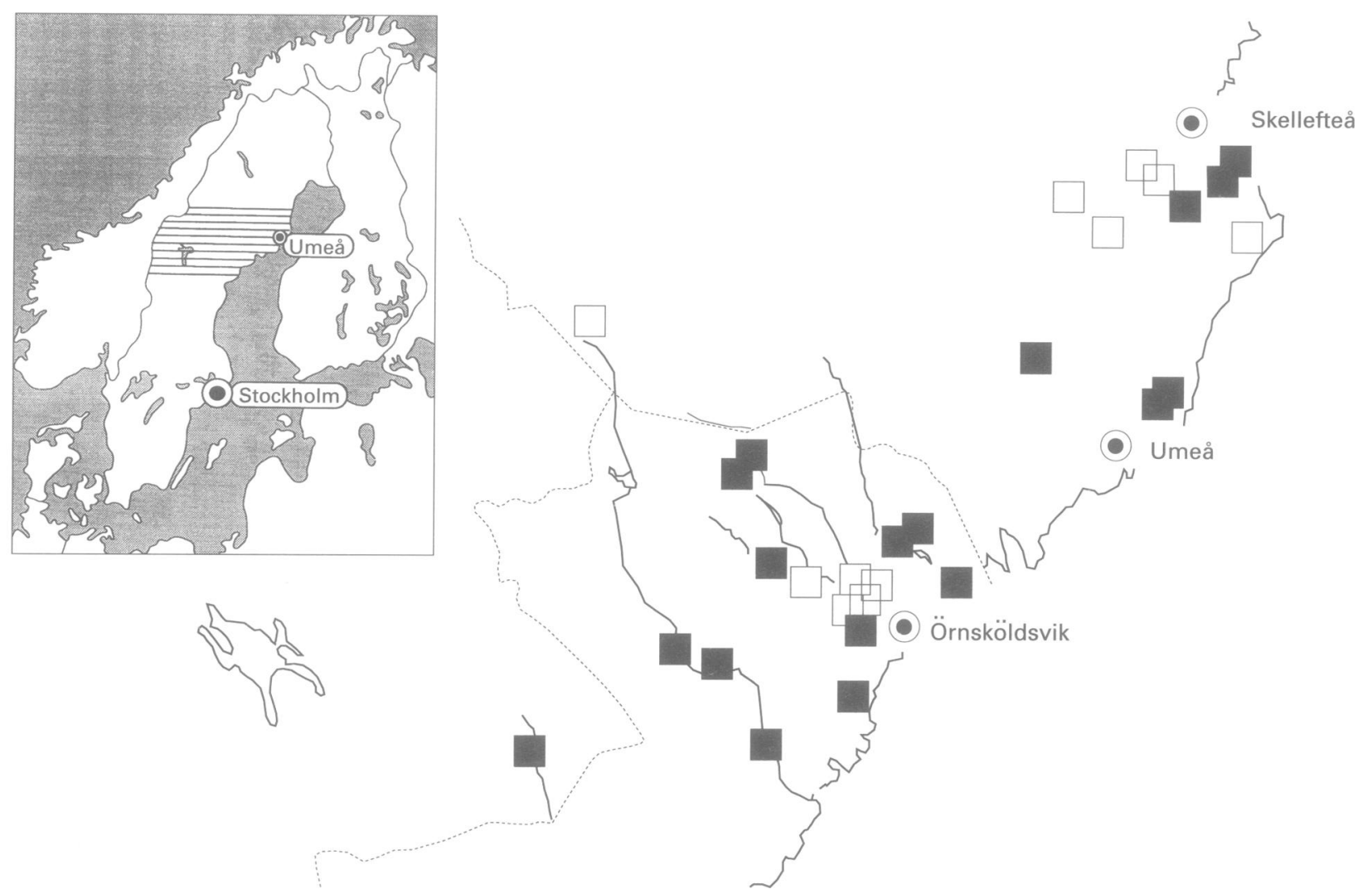

Figure 2 Map of northern Sweden indicating the places of birth of the parents of patients ( $A$ to I) (filled squares) and the places of residence of the key families (O to Z) (unfilled squares)

Church. ${ }^{16}$ These records, as well as other systematically related records of births, marriages, and deaths, make it possible to establish family links between people living more than 200 years ago and those of the recent past. ${ }^{15}$ The mode of inheritance was estimated according to the "sib" method. ${ }^{17}$

Simulation studies were performed using the SLINK program package ${ }^{1819}$ under the assumption of an autosomal recessive gene with full penetrance. The number of people analysed in the simulation was 156 of whom 51 were in the category marker available. One hundred replicates were generated with a four allele marker, with allele frequencies of 0.25 each, at $5 \mathrm{cM}$ of the disease locus.

\section{Results and discussion}

All nine families with HML patients could be genealogically linked to one or two of the other families involved in the study, and pointed to some genetically interesting links with some of the key families back in time. Attempts to trace the nine families back in time to a common single key family have so far not been successful (fig 1). The mode of inheritance is in accordance with autosomal recessive inheritance (confidence limits $0 \cdot 22-0.54$ ) (table).

Genealogical research on a disease with proven dominant inheritance and with high penetrance often makes it possible to confirm the appearance of the disease among ancestors one or a few generations back in time using medical journals or other records or through interviews with family members. This is prac- tically impossible when dealing genealogically with autosomal recessive diseases like the one studied here. In order to make use of genealogical data in this connection, there are some general, but hitherto seldom considered aspects to be discussed. The possibility of finding any key family of genetic significance will be maximised by using all known families with patients with the disease for genealogical studies. Pedigrees involving only a couple of families are a weak basis for genealogical analysis. The use of reference genealogical studies from the same geographical regions make it possible to discuss validity aspects of the results found. Owing to the relative immobility of the population in northern Sweden until lately, close links among people from the same region are common in rural areas, and could explain the consistency of pedigrees.

Certain specific ancestral lines are in general more reliable than others. For instance those involving close links between families studied are more reliable than more dispersed ones. Ancestral lines involving females are generally more reliable than those involving males, because of the effects of illegitimate children or discrepancies between de facto and de jure fathers.

The present genealogical analysis includes all known Swedish families with patients with HML. The number of links found between the separate families is not exceptional for genealogical studies in northern Sweden. ${ }^{8}$ However, the families studied do not come from one single geographical area. Both the separate patient families $A$ to $I$ and the key families $O$ 
to $Z$, to whom they are linked, at least in pairs, are domiciled in two separate areas to the north and south in the following way. While both parents of families $A$ and $F$ and the key families $\mathrm{O}$ to $\mathrm{S}$ come from the northern area, families $B$ to $E$, and $G$, and key families $T$ to $Z$ come from the southern one. The mother of family $\mathrm{H}$ and the father of family I come from the southern area while the other two parents in these families come from the northern area (fig 2).

As can be seen in fig 2, birth places of parents of patients were concentrated in two distinct areas. Moreover the concentration of places of residence for the key families $O$ to $Z$ is even more confined. In fact a majority of these places of residence are situated in just two separate parishes, that is, $\mathrm{O}$ to $\mathrm{R}$ in the north, and $\mathrm{T}$ to $Z$ in the south. Hereditary diseases are typically found along the rivers in northern Sweden, often along one single river valley. ${ }^{20}$

From the discussion outlined above some sections of the pedigree seem more genetically promising as a basis for further analysis than others. The parents of family $\mathrm{E}$ were first cousins, and a common link to family $U$ both to these first cousins and to the father of family $\mathrm{B}$ has been found. Furthermore, both parents of family A and the father of family I are linked in a rather complicated way to the two key families, $\mathbf{R}$ and $\mathbf{S}$. Family $\mathbf{R}$ is also linked to the mother of family $\mathrm{H}$ in a female dominated ancestral line.

In order to determine the power of this family pedigree in linkage analysis, simulation studies were performed using the SLINK program package. ${ }^{1819} \mathrm{~A}$ single autosomal recessive gene was assumed and the simulation was run with 100 replicates assuming a four allele marker at $5 \mathrm{cM}$ of the disease locus. The total number of people in the pedigree was 156 of whom 51 were in the category marker available. A maximum lod score of 5.74 and a mean lod score of 2.85 were reached. The probability that the lod score would exceed the threshold values 1,2 , and 3 was $94 \%, 76 \%$, and $50 \%$ respectively. This simulation shows that the families reported in this study are powerful enough to use in linkage analysis under the assumption of homogeneity. The maximum lod score obtained, $5 \cdot 74$, is well above 3 , which is the accepted significant level for linkage. Furthermore the probability of achieving a lod score over 3 is $50 \%$ and the mean lod score is very close to the significant level.

Pedigrees have hitherto been mostly used as mere illustrations of heredity and as diagnostic tools in clinical practice. Thus, the pedigrees confirmed that the sporadic patients of families $\mathrm{E}, \mathrm{F}, \mathrm{H}$, and I had a hereditary disease of the same type as that of several sibs with the disease in families $A$ to $D$ and $G$. But pedigree analyses concerning disease with probable recessive inheritance can also serve as tools or as empirical grounds for strategic selections of certain key groups of patients represented in the pedigrees for further molecular biological analyses, in order to locate the gene.

We thank the members of the HML families for their participation in the study. We also thank Mrs Margit Lundmark for excellent technical assistance and genealogist Tom Jusslin for collecting parish register data. This project was supported by the Swedish Medical Research Council (Project No 09745), and the Faculty of Medicine, University of Umeå, Sweden.

1 McKusick VA. Mendelian inheritance in man 10th ed. Volume 2. Baltimore: The Johns Hopkins University Press, 1992 2 Larsson LE, Linderholm H, Müller R, Ringqvist T, Sörnäs R. Hereditary metabolic myopathy with paroxysmal myoglobinuria due to abnormal glycolysis. $\mathcal{F}$ Neurol Neurosur Psychiatry 1964;27:361-80.

3 Linderholm H, Müller R, Ringqvist T, Sörnås R. Hereditary abnormal muscle metabolism with hyperkinetic circulation during exercise. Acta Med Scand 1969;185:153-66.

$4 \mathrm{Linderholm} \mathrm{H}$. Special type of myoglobinuria in Northern Sweden. In: Bylund E, Linderholm $\mathrm{H}$, Rune $\mathrm{O}$, eds. Ecological problems of the Circum polar area. Papers from Ecological problems of the Circum polar area. Papers from
the International Symposium at Luleå, Sweden, 1971 June 28-30. Lulea: Alltryck, 1971 .

5 Linderholm H, Essén-Gustavsson B, Thornell LE. Low succinate dehydrogenase (SDH) activity in a patient with a hereditary myopathy with paroxysmal myoglobinuria. $\mathcal{J}$ Intern Med 1990;228:43-52.

6 Haller RG, Henriksson KG, Jorfeldt L, et al. Deficiency of skeletal muscle succinate dehydrogenase and aconitase. Pathophysiology of exercise in a novel human muscle oxidative defect. F Clin Invest 1991;88:1197.

7 Hall RE, Henriksson KG, Levis SF, Haller RG, Kennaway NG. Mitochondrial myopathy with succinate dehydrogenase and aconitase deficiency. Abnormalities of several ion-sulphur proteins. F Clin Invest 1993;92:2660-6.

8 Drugge U, Andersson R, Chizari F, et al. Familial amyloidotic polyneuropathy in Sweden: a pedigree analysis. $\mathcal{f}$ Med Genet 1993;30:388-92.

9 Holmgren G, Blomquist Kson H, Drugge U, Gustavson $\mathrm{KH}$. Fragile $\mathrm{X}$ families in a northern Swedish county. A genealogical study back to the beginning of the 18th century demonstrating paternal transmission. $A m \mathcal{F} M e d$ Genet 1988;30:667-73.

10 Linderholm H. Dependence of maximum performance time on work intensity in patients with a hereditary myopathy with succinate dehydrogenase deficiency. Clin Physiol 1992;12:567.

11 Wahren J, Linderholm H, Felig P. Amino acid metabolism in patients with a hereditary myopathy and paroxysma myoglobinuria Acta Med Scand 1979;206:309-14.

12 Linderholm H, Almay B, Bäcklund U, et al. Ärftlig myopat med succinatdeydrogenasbrist - en sällsynt sjukdom som kan bli livshotande. Läkartidningen 1992;89:1283 (summary in English).

13 Linderholm H. Hyperkinetic circulation. In: Hainsworth R, Mark AL, eds. Cardiovascular reflex control in health and disease. London: Saunders, 1993.

14 Linderholm $\mathrm{H}$. A hereditary mitochondrial myopathy with low succinate dehydrogenase activity in northern Sweden. In: Post BD et al, eds. Circumpolar health 90. Winnipeg University of Manitoba Press, 1991. Anctic Medical Research, Suppl 5, 1991.

15 Sandgren O, Drugge U, Holmgren G, Sousa A. Vitreius involvement in familial amyloidotic neuropathy: a genealogical and genetic study. Clin Genet 1991;40:452-60

16 Johansson E. Literacy campaigns in Sweden. In: Arnove RJ $\mathrm{Graff} \mathrm{H}$, eds. National literacy campaigns. Historical and comparative perspectives. New York: Plenum Press, 1987: 65-98.

17 Emery AEH. Methodology in medical genetics. Edinburgh: Churchill Livingstone, 1976:35-50.

18 Ott J. Computer-simulated methods in human linkage analysis. Proc Natl Acad Sci USA 1989;86:4175-8.

19 Weeks DE, Ott J, Lathrop GM. SLINK: a general simulation program for linkage analysis. Am $\mathcal{F}$ Hum Genet 1990;47: A204.

20 Sousa A. Andersson R, Drugge U, Holmgren G, Sandgren $O$. Familial amyloidotic polyneuropathy in Sweden: Geographical distribution, age of onset and prevalence. Hum
Hered 1993;43:288-94. 